\title{
PASUGIHAN ORANG BANJAR: Studi Identifikasi Prilaku dan Amaliah Pasugihan Orang Banjar di Kalsel
}

\author{
Abd. Sani \\ Dosen Jurusan Akidah Filsafat Fakultas Ushuluddin dan Humaniora \\ IAIN Antasari Banjarmasin
}

\begin{abstract}
'Pasugihan' of Banjar people (getting wealth by unusual ways) intended in this paper is three prototypes. First, the wealthy Banjar people (wealth and money). But, they get it through the 'left-way', which maintains genies (genie mating), spirits (tuyul), stealth swine (Babi ngepet), usues Kuyang oil, and etc. Second, they take the wealth through the 'right-way', which gets the wealth by doing Islamic ritual, such as fasting and reading sura Waqiah, doing Dhuha prayer, reading sura Alfatihah, even combining with Lailatul Qadr. This group also includes its own myth in society's view of Banjar people. Third, the rich people who gets the wealth mythology irrational and rational. Most of this paper is the result of qualitative research methodology by relying interview techniques.
\end{abstract}

Kata kunci: pasugihan, amaliah, legenda, kekayaan.

\section{Pendahuluan}

Orang kaya baru (OKB) masyarakat Banjar dalam sepuluh tahun terakhir ini semakin banyak dan meningkat, itu bisa diidentifikasikan dalam secara kasat mata berdasarkan mobil mewah yang banyak berseleweran di jalan, banyaknya rumah-rumah mewah, apartemen dan villa serta berbagai jenis usaha dan perusahaan yang di bangun baik di kota Banjarbaru maupun Banjarmasin.

Indikator lain, $\mathrm{OKB}$ yang muncul itu juga berarti ada terjadi peningkatan pengeluaran dan pendapatan secara keuangan, terbukanya lapangan pekerjaan bagi kelompok lain, dan kepemilikan harta kekayaan yang luar biasa dalam kebendaan, tingkat daya beli terhadap barang mewah lainnya, serta banyaknya orang melakukan umrah maupun berhaji setiap tahun. Berdasarkan pelaporan keuangan mendekati Ramadhan dan menjelang hari raya, uang yang beredar setiap hari ratusan milyar, bahkan di hari $\mathrm{H}$ di atas 1 triliyun. ${ }^{1}$

Gambaran itu memang bersifat relatif tentang $\mathrm{OKB}$, namun paling tidak dapat teramati di bagian terkecil dari kehidupan lingkungan tinggal di tingkat RT (rukun tetangga) telah terjadi peningkatan gaya hidup secara material Hanya saja mengukur kekayaan dan keuangan berdasarkan produk barang mewah, penampilan, gaya hidup kelas sosial mungkin belum bermakna dapat mengungkapkan secara akurat apalagi secara ilmiah, diperlukan langkahlangkah pengamatan seksama dan penelitian yang cukup mendalam, agar dapat mengungkapkan secara detail gambaran angka-angka pasti tingkat kekayaan yang pasti.

${ }^{1}$ Banjarmasin Post Edisi 20 Agustus 2013 tentang berita beredarnya uang di Kalsel menjelang Hari Raya Idul Fitri Tahun $1434 \mathrm{H}$. 
Berbagai gambaran orang kaya banyak cerita bahkan legenda yang mendekati mitos bahwa orang yang kaya raya luar biasa yang manakala kekayaan itu dimakan, tidak akan dapat dihabiskan sampai tujuh turunan sekalipun Gambaran spektakuler tentang orang kaya dimaksud tentu ada kecurigaan dan ada "apa-apanya" Penulis teringat beberapa cerita masa lampau di kampung halaman di wilayah Kecamatan Danau Panggang, dan beberapa kali penjajakan di lapangan sebagai studi pendahuluan tulisan ini, tergambarkan, bahwa orang yang kaya raya dan memiliki banyak kemewahan hidup — termasuk tentunya banyak uang — tidak bisa dipungkiri jelas memiliki ilmu untuk mendapatkannya. Ilmu itu banyak yang terkait dengan ilmu berusaha atau berdagang maupun ilmu-ilmu gaib yang berkaitan dengan cara mendapatkan kekayaan dan uang itu.

Beberapa gambaran jenis prilakunya, ada orang kaya yang memang menjalankan usaha secara normal, namun dekat dengan banyak tuan guru, para ahli spiritual dan ahli hikmah (ahli mengamalkan wirid Islami untuk mendapatkan kekayaan), menjalankan ritual, balampah bahkan ada juga yang bersahabat dengan jin, menjadi pasugihan setan gundul, babi ngepet, memelihara tuyul, kandang bubrah dan memiliki berbagai minyak penglaris (minyak kuyang), minyak hantu baranak, minyak Nabi Sulaiman, Jimat Qarun, dan lain sebagainya

Di antara jenis usaha mendapatkan kekayaan dan uang itu ada yang disebut dengan istilah “jalan kiri, jalan kanan, dan jalan lurus”, Kalau jalan kiri jelas dengan menggunakan sarana gaib yang sama sekali tidak ada kaitannya dengan ajaran Islam, sementara jalan kanan dengan mnggunakan sarana ritual atau ditambah doa-doa Islami, seperti salat hajat, salat Dhuha, tahajut, puasa Senin- Kamis, membaca surah Al-Waqiah 1000 kali, surah Al-fatihah 100 kali setiap hari, salawat Nariyah 4444 kali berjamaah setiap malam Jumat, wirid-wirid dan doa tertentu, memberi makan pakir miskin (anak yatim) setiap Jumat dan lain-lain sebagainya. Sementara yang disebut kaya raya jalan lurus adalah berusaha apa adanya tetapi memang secara banyak kebetulan menjadi kaya raya tanpa dibarengi tetek-bengek persyaratan untuk menjadi kaya, seperti tiba-tiba mendapatkan warisan orang tua, yang secara nalar susah dicerna, mendapatkan undian tertentu atau apa saja yang menjadi sebab kaya raya, dan yang bersangkutan tidak terlalu peduli tentang cara mendapatkan kekayaan. Artinya secara suratan takdir memang terlahir menjadi orang kaya dan banyak uangnya, dan yang bersangkutan bekerja biasa-biasa saja hanya mengandalkan kemampuan ilmu berdagang semata, ini termasuk kelas orang yang berusaha di jalan lurus, tanpa susah payah, tetap kaya raya, bahkan mungkin tanpa memiliki usaha ke kiri dan ke kanan, ini yang disebut dalam istilah kelas sudah termasuk kelas "dijamak Tuhan atau dijamak Jibril" yang hanya orang-orang tertentu saja yang mendapatkannya.

Persoalannya di tingkat kasb (kelas pekerja) manakala terjadi gambaran orang yang memiliki kekayaan luar biasa pasti ada terjadi tudingan mereng bahwa orang itu memiliki pasugihan, dan macam-macam "Tidak mungkin kalau hanya mengandalkan badagang, bisa baduit triliyunan, pasti ada apa-apanya, komentar Kadir, salah seorang teman yang ditanya tentang orang Banjar sekarang yang muncul menjadi milyuner baru.

Mengungkap tentang simbol-simbol orang Banjar tentang kekayaan mungkin bisa dan dapat melacaknya, walaupun memerlukan waktu lama dan penelitian yang mendalam, banyak tantangan yang mesti dilalu, namun juga tidak menutup kemungkinan dengan menggunakan berbagai pendekatan yang lebih intensif dan kekeluargaan akan lebih dapat mengungkap secara real tentang berbagai gambaran jalan orang mendapatkan kekayaan. 
Selama ini tidak bisa dimungkiri Islam sendiri mewariskan nilai-nilai ajaran dan nilai-nilai spritualis tentang jalan-jalan yang ditempuh seseorang untuk mendapatkan harta benda dan kekayaan, sepanjang jalan itu, jalan lurus dan jalan kanan, maka syah-syah saja bahkan justru dengan banyaknya orang Islam yang kaya raya akan memberikan dampak perubahan ke masyarakat, seperti banyaknya orang Islam bersedakah dan berzakat, yang berimbas pada terjadi efek kesejahteraan terhadap umat Islam yang lain.

Ajaran Islam yang terkait dengan berbagai mendapatkan kekayaan bahkan cara mendapatkan uang halal secara gaib, bahkan ada yang menisbahkan kepada ajaran-ajaran hikmah seperti kitab ilmu gaib "Kitabul Aufaq" karya Imam Al-Ghazali, ${ }^{2}$ yang popular dengan berbagai keilmuan kuno tentang amalan yang dianggap Islami, cara-cara mendapatkan harta benda dan keuangan, dengan berbagai rangkaian ritual serta puasa khusus, uang itu dapat dating dengan sendirinya, karena mampu memanggil khodam uang dan nama-nama penunggu khas harta benda terpendam di dalam alam gaib, maupun Harta Karun yang tertimbun ribuan tahun Menurut Brujomusti seorang pakar spiritual khusus pesugihan Islami, ritual tertentu dapat mendatangkan uang dalam waktu sekejap bahkan dapat membelanjakan uang, yang kemudian uang hasil riual itu bisa kembali lagi setelah dibelanjakan dalam istilah Jawa disebut "uang balen", yang dalam sehari dibelanjakan sebanyak 40 kali terhadap uang uang tidak berzakat, apalagi makin ampuh cara kerjanya ${ }^{3}$. Ada kitab salinannya berbahasa Indonesia-Jawa yang dikarang oleh Ahmad Thoha Abdul Ghani, juga membeberkan cara-cara meritualisasikan pasugihan Islami, dengan berbagai lampahan dan seremonial sebagai prasyarat mendapatkan kekayaan atau uang dengan masih berpegang pada tradisi Islam dan tradisi para ulama dan wali Songo di Tanah Jawa ${ }^{4}$.

Problem sekarang ada beberapa anggapan sementara, apakah berbagai pesugihan itu benarbenar sesuai ajaran Islam dan tidak melanggar ajaran Tauhid secara teologis? Sementara pada sisi lain banyak anggapan miring di masyarakat bahwa yang namanya bentuk pesugihan itu terkait hubungan dengan jin dan berbagai tumbal baik nyawa manusia maupun tumbal hewan seperti kambing hitam, sapi betina dan lain-lain. Namun masih ada keraguan manakala pesugihan itu tidak tumbal, dan kekayaan yang didapat benar-benar pemberian makhluk halus baik jin, khodam maupun malaikat yang tunduk baik ditaklukan maupun atas kemauan mereka sendiri. Mereka itu memberikan berbagai kemudahan kepada seseorang yang "sakti" atau tuan guru berkeramah tinggi tanpa dimintai sama sekali, apakah jenis pesugihan itu boleh atau bagaimana?

Anggapan berikutnya kekayaan atau uang yang didapatkan dengan cara pasugihan dianggap milik seseorang atau milik bank misalnya, apakah dengan jalan mengambilnya dianggap boleh, kalau berbentuk uang tentu milik orang lain atau milik bank apalagi diambil dalam jumlah besar sampai miliyaran rupiah, Bagaimana hukum yang sesungguhnya? Walaupun kajian hukum halal-haram seperti sudah jelas bahwa setiap benda atau uang yang bukan milik sendiri dan diambil dianggap sebagai pencurian. Pencurian sesuatu tetap dihukumkan haram Berbagai cerita bahwa bank sering kehilangan uang dalam jumlah besar seperti di Bali beberapa bulan

${ }^{2}$ Imam al-Ghazali, Kitabul Aufaq, (Aneka Solo, 1989), h. 15-19.

${ }^{3}$ Brujomusti, Pakar Pasugihan Lampung, (edisi Liberty 443, 2013), h. 69-70.

${ }^{4}$ Ahmad Thoha Abdul Ghani, Pesugihan Islami, Pedepokan dan Majlis Zikir Sapujagad Jaya Pamungkas, (Bintang Songo Boyolali, 2011), h. 17. 
yang lalu, seharinya mencapai ratusan juta rupiah Peristiwa itu dianggap sebagai akibat ada yang melakukan praktik pesugihan jenis leak (mirip pasugihan kuyang). Katanya di berbagai bank di wilayah kita juga pernah kejadian-kejadian hilangnya uang, cuma beritanya tidak dibuat di media massa, supaya jangan menimbulkan kepanikan dan kecemasan terhadap nasabah yang menitipkan tabungannya di bank.

Peristiwa pesugihan selama ini menarik dikaji karena memiliki daya ekspos yang kelam atau tidak terbuka, pelaku tidak ingin diketahui, namun lambat masyarakat sekitarnya akan mendapatkan informasi tentang prilaku pesugihan seseorang, apalagi kalau pesugihan itu dengan jalan menyimpang dan memiliki tumbal. Anggapan adanya prilaku pesugihan yang para tokoh orang kaya terkenal, memang selama masih hidup banyak tidak terungkap, namun setelah yang bersangkutan meninggal dunia, baru heboh dan menjadi berita dari mulut ke mulut dan akhirnya tidak menjadi rahasia lagi. Apakah benar setiap bentuk kekayaan seseorang yang luar biasa banyaknya melimpah ruah merupakan bentuk pesugihan? Selanjutnya apakah setiap bentuk pesugihan yang luar biasa, dianggap bentuk pesugihan "jalan kiri”.

Bagaimana tentang pesugihan dengan menggunakan ritual puasa, wiridan, wifik, azimat, pusaka ampuh, minyak-minyak lampahan dan lain-lain sebagainya, apakah tidak sesuai dengan ajaran Islam, atau sebaliknya boleh-boleh saja? Analisis mendalam dan tajam diperlukan untuk menyingkap berbagai ajaran pesugihan dan berbagai ritualisasinya. Untuk itu dikemukakan pertanyaan beberapa hal: Bagaimana gambaran identifikasi pesugihan orang Banjar? Faktor dominan apa saja yang mendorong orang Banjar melakukan praktik pesugihan dimaksud?

Mengingat topik tulisan ini memiliki tantangan tersendiri dan memiliki kronik problematika yang tinggi, maka diperlukan pembatasan masalah dan ruang lingkup kajian wilayah lokasi, yaitu ada beberapa istilah yang dibatasi :

1. Pasugihan atau pesugihan, istilah di dalam tulisan ini adalah orang yang memiliki kajian untuk kaya raya dan banyak uang yang secara jahir sangat luar biasa dan spektakuler dalam tempo relatif singkat, meliputi jalan pesugihan ke kiri, ke kanan Kalau jalan lurus tidak terlalu menjadi fokus bahasan.

2. Orang Banjar dalam uraian ini diarahkan kepada personal warga Banjar baik asli maupun keturunan, namun dominan etnisnya sudah termasuk orang asli bertempat tinggal dan lahir sebagai suku Banjar khas, menurut istilah Alfani Daud, merujuk kepada etnis orang Banua (bububan pabuluan), namun dalam konteks lokal adalah penduduk yang menempati wilayah Kalimantan Selatan sebagai warga peranakan Banjar asli maupun keturunan.

3. Istilah dalam kurung yaitu ada beberapa suku kata yang jelas sebagai fokus kajian seperti identifikasi bisa dimaknakan ciri atau pelacakan terhadap ciri-ciri seseorang terutama menyangkut ciri khas pada status sosial di dalam kekayaan dan berlimpahnya uang adapun prilaku sudah lazim diketahui artinya, tidak terlalu jauh baik secara teks maupun konteks penelitian sementara istilah amaliah merujuk kepada kajian atau ilmu tentang pesugihan dalam berbagai aspeknya.

4. Adapun pembatasan lokasi penelitian dalam kaitan wilayah difokuskan pada tempat tinggal pelaku pesugihan untuk lokasi berada di Banjarmasin, Binuang, Amuntai, Pelaihari dan Batulicin Lokasi tempat tinggal lebih memudahkan dalam pembatasan ruang lingkup tugas penelitian di lapangan. 
5. Tulisan ini sebagai masukan dalam penyebaran keilmuan (ilmiah) antara lain sebagai berikut:

a. Secara ilmiah dapat dijadikan bahan kajian dan referensi untuk membuktikan bahwa nilai-nilai pesugihan itu benar-benar ada dan dapat dipertanggungjawabkan, bahkan dapat dijadikan sumber inspirasi bahwa jalan-jalan mendapatkan kekayaan dan uang ada yang instan, tetapi ada juga yang berliku-liku dan penuh tantangan besar

b. Menjadi semacam sumbangan teoritik bagi melacak bentuk-bentuk pola identifikasi kajian ilmu sosial terhadap prilaku orang Banjar, yang selama ini terabaikan dalam pengamatan penelitian.

c. Dapat dijadikan "buku atau rujukan" pembanding, sekaligus mendorong mentalitas kritis bagi berbagai kalangan untuk tidak sekadar cerita bahkan isapan jempol, namun perlu pembuktian ilmiah dan perlu cara-cara pengungkapan kajian penelitian bidang sosial dengan metode sekaligus strategi tertentu yang dapat dipolakan acuannya Karena selama ini prilaku masyarakat atau orang perorang menjadi hanya sebuah gosif yang bisa jadi berdampak negatif kalau tidak mampu terungkapkan secara ilmiah dan dalam rambu-rambu keilmuan tertentu.

\section{Metode}

Pembahasan ini menggunakan pendekatan kualitatif (karena sebagian merupakan summary penelitian), yaitu dengan berusaha berpegang kepada kaidah rambu-rambu penelitian dengan beberapa langkah. Mengapa dilakukan penelitian kualitif, karena sebagaimana Moleong (1996) agar "kekayaan" ungkapan emik dan etik dapat mewakilkan uangkapan yang tersembol ke permukaan dan prilaku, sikap, keterwakilan simbol-simbol pandangan sekaligus prilaku dapat terwakilkan apa adanya dari sumber data yang jadi bahan penelitian,

Kelebihan penelitian kualitiatif akan memberika deskripsi detail, tajam, mendalam dan memiliki informasi analisis yang tinggi dalam penjabaran pelaporan hasil olah penelitian secara komprehensif

Beberapa langkah penelitian kualitatif antara lain:

1. Obyek dan subyek Data

Obyek data yang akan dijadikan bahan data adalah prilaku dan amaliah pesugihan, seperti bentuk ajian-ajian, amalan-amalan, ritual-ritual, seremonial serta media-media perantara pesugihan itu sendiri baik ada benda atau pusaka, atau perantara orang gaib, jin dan makhluk halus lainnya, sedangkan subyek data identitas orang Banjar sebagai pelaku pesugihan bentuk-bentuk fenomena lainnya yang bisa diamati secara kasat mata selaku personal orang Banjar.

2. Data dan Sumber data

Data penelitian adalah jenis-jenis pesugihan kiri, ini didapatkan dalam bentuk kajian pustaka seperti pesugihan Syaitan Gundul, Babi Ngepet, Pesugihan Tuyul, Kawin dengan Jin, Pesugihan Ratu Pantai Selatan, Pesugihan Dewi Lanja Ratu Pantai Utara, Pesugihan Minyak Kuyang, Minyak Hantu Briaban, dan berbagai kajian dari sejumlah ajian pesugihan yang dianggap tidak lazim atau menyimpang.

Data pesugihan kanan ada yang sebagian dari referensi buku, brosor maupun iklan media massa sumber amaliah Alquran dan hadis, warisan ajian ulama klasik dan terutama 
ulama walisongo, Amaliah tirakat (balampah) wifik, khodam Alquran, salat hajat, Duha, salawat fulus, salawat nariyah, khodam surah AlFatihah, Al-Ikhlas, amaliah member makan anak yatim, serta deskripsi biografi singkat orang kaya Banjar serta pola pesugihan mereka.

Sumber data adalah para pelaku pesugihan, informan kunci, sebagai responden atau pemberi sumber data utama, guru spiritual mereka dan orang-orang yang banyak mengetahui tentang sosok tokoh pelaku pesugihan.

3. Teknik penggalian data

a. Teknik observasi dilakukan dengan cara pengamatan langsung untuk menggambarkan tentang situasi dan kondisi rumah tangga, kekayaan dan bidang usaha yang dapat diamati secara indrawi, termasuk melakukan observasi terhadap sumber-sumber inspirasi atau guru spiritual mereka.

b. Wawancara mendalam dilakukan untuk mendapatkan data tajam terpecaya dan akurat dengan berusaha mengadakan tatap muka, komunikasi elektronik multi media), dengan strategi terbuka maupun tertutup artinya diperlukan strategi dialogis dan pendekatan kekeluargaan yang simltan dan dengan volume waktu lama, agar berhasil menggali secara cermat data utama yang tidak bisa digali dengan teknik observasi maupun teknik lainnya.

c. Dokumentasi, atau proses pendokumentasian bahan-bahan penelitian untuk bukti visualisasi dan audio dengan pemotretan gambar, perekaman suara dan bahan-bahan tertulis lainnya yang dapat menunjang bukti penelitian ini.

4. Analisis Data

Analisis data dilakukan secara induksi dan didukasi terutama data yang didapatkan perlu dianalisis prioritas klasifikasi keutamaannya, setelah itu dilakukan rekayasa kodifikasi naratif pembukuan agar pemilahan data dapat cermat dan terarah pengorganisasiannya Pengelolaan data yang sudah memiliki tema-tema tertentu sesuai kehendak peneliti, maka dicoba membahas satu-persatu dan dilakukan analisis sementara seperti yang dilakukan oleh Moleong (1996) atau oleh L, Guba (1991) dalam penelitian Naturalistik, yaitu antara data deduktif dan data induktif dapat diklasifikasikan kategorinya dengan jelas berupa mana data induktif — data alamiah—, sementara data deduktif data yang sudah diberikan kesimpulan-kesimpulan sementara sebelum tertuang secara analisis berdasarkan pendapat yang sudah diuraikan dengan bantuan pustaka dan kajian teoritik referensial baik referensi teks maupun "teori postulat hipotesis peneliti yang berkembang pengayaannya saat berada di lapangan $\mathrm{Hal}$ ini biasa terjadi dalam penelitian ilmu socsal yang menggunakan strategi grounded seperti Kontjaraningkat, C Geertz, Selo Soemardjan dalam penelitian Antropologi Sosial, yang mana mereka berusaha merekonstruksi teori baku menjadi teori sambil jalan saat penelitian berlangsung, kadangkala konsep-konsep bermunculan saat berlangsung penggalian data, dan konsep itu perlu dijadikan arah bahan inspirasi pengajuan pertanyaan atau pondasi sementara yang seakan-akan dianggap teori.

Analisis akhir dilakukan untuk kroscek data, validasi, ujicoba kebenaran dari berbagai pihak dan sumber, agar data yang didapat tidak mengambaikan kepentingan ilmiah obyektif. 
Analisis sampai kepada penyajian data naratif berbentuk deskripsi naskah merupakan hasil saringan berbagai bahan temuan dan sudah mengalami pembauran dengan sejumlah teoritik sekaligus dengan bahan temuan lapangan, dan pembahasan analisis data berupa pertopik maupun pembahasan menyeluruh (komprehensif) terhadap bahan data yang sudah dimatangkan.

Beranjak dari pembahasan itu dilakukan simpulan penelitian secara point perpoint sesuai aspek-aspek data penelitian yang sudah diolah oleh peneliti menjadi pelaporan akhir.

\section{Pembahasan dan Analisis}

Pembahasan dalam uraian tulisan ini lebih dititikberatkan kepada gambaran mendapatkan kekayaan dalam jalan-jalan paranormal dan metarasional (sebagian tidak rasional). Artinya selain mitos yang muncul dan pembuktian lisan dari guru, teman sejawat yang masing-masing sama-sama "mengaji" basuhu, atau teman akrab yang menjadi bawahan, hampir dapat dipastikan tidak memiliki pengakuan langsung dari kunci responden data utama. Sumber-sumber yang dapat dipercaya sekalipun mereka tetap mewanti-wanti tidak ingin namanya disebut secara gamblang. Termasuk subyek pelaku pesugihan, juga dalam penggalian data kami samarkan. Atas saran keluarga dekat, tetangga, supir, pembantu, karyawan, dan tenaga kerja lepas pada subyek yang diamati. Berdasarkan itu didapatkan informasi sebagai berikut:

\section{Pasugihan jalan kiri}

Berdasarkan wawancara sejumlah guru spiritual yang mengajarkan, membimbing dan sekaligus membawa "berguru" lagi kepada guru yang lebih tinggi, didapatkan data yaitu; pelaku pesugihan ada yang memelihara minyak kuyang, yaitu semacam miyak asli warisan Dayak pedalaman Kalimantan entah di Kaltim, Kalbar atau Kalteng.

Menurut sumber utama yang dapat dipercaya, sebut Tugat (nama samaran), minyak ini didapat di pedalaman hulu Kalteng dari suku asli Dayak. Minyaknya berwarna hijau kebirubiruan dan sanggup mendapatkan uang dalam jumlah banyak, kalau duit yang kita belanjakan dilampahi dan kemudian minyak itu dioleskan ke lembaran uang dalam waktu tidak lama akan kembali ke pemilik minyak kuyang. Kebetulan Tugat memiliki dangsanak orang Dayak pendalaman. Banyak orang Banjar yang memahari (menebus), terutama mereka yang kepepet hutang menumpuk atau sedang ditipu orang dalam berbisnis. Dua orang temannya pernah mengambil, dan sampai sekarang masih kaya raya, mereka sebut saja MUHA dan HAHA (nama singkatan samaran tinggal di daerah Tanah Laut dan Pulau Laut). Menebus maharnya lumayan mahal hampir 13 jutaan perbotol (kurang lebih 5 gram, hampir sama dengan satu botol minyak angin). Pengusaha yang disebutkan di sini memang dipantau rumahnya besar, besi, batu latrit (tanah kuning) sembako, makelar tanah, dan jual beli emas di pandulangan.

Minyak kuyang memerlukan tumbal, berupa kerbau merah seharga 35 juta perekor untuk kurban setiap tahun. Tapi memang ada resiko tinggi, kalau lupa menyerahkan tumbal, jin pemilik minyak kuyang akan mengambil nyawa pelaku pesugiban.

\section{Pesugihan kedua}

Menjadi budak jin babi ngepet, yaitu sejenis pesugihan memelihara babi. Padahal babi itu tidak berwujud selayaknya binatang hanya jelmaan siluman babi. Uniknya cara memelihara 
binatang babi dalam kamar khusus, dan tidak seperti babi ngepet yang harus suami isteri, ini cukup dilakukan oleh si suami penganut pesugihan, sementara suami keluar rumah di malam hari menjadi babi dan mengambil uang orang. Jenis pesugihan ini cukup mengadakan perjanjian bersedia memelihara jenis genderowo (menyerupai binatang babi). Berdasarkan wawancara dengan orang seperguruan yang sama-sama mengaji ke tanah Jawa, ada dua orang yang mengaji ini dan berada di daerah pedalaman serta orang itu sering berpindah-pindah rumah karena mengikuti usaha bisnisnya. Pak Sudin, nama samaran teman seperguruan berkebangsaan Banjar Sulawesi. Pernah gagal mengaji itu. Maharnya menebus ilmu dan membawa jenis jin pesugihan sekitar 7 juta atau dua ekor sapi jantan dan batina. Pak Sudin, gagal karena saat dirakat di dalam kabar khusus gurunya, di daerah Jawa Timur sana, tanpa sadar terkejut saat tergelincir di dalam kamar karena semen becek ada lumutnya, mengucapkan Allahu Akbar, maka sejak mengucapkan itu, ia merasa berdosa terus-terus, sampai protes ke guru spiritualnya, minta ganti biaya ritual. Akhirnya dikembalikan Rp. 3. 500.000,-.

Temannya yang kedua-duanya sukses sampai sekarang kaya raya dan memiliki uang ratusan milyar. Usaha bisnis tetap dilakukan sebagai kedok pesugihan.

Pesugihan berikut ini terkait dengan memelihara jenis jin lutung kesarung, yaitu sejenis jin yang menyamar sebagai siluman menyerupai monyet atau gorila berbulu lebat. Kajian ini diambil di tanah Jawa, wilayah pegunungan keramat seperti gunung kawi, dan lain-lain. Kalau juru kunci pembimbing spiritual dapat mempertemukan dengan penunggu salah satu alas gunung, maka dipastikan tidak berapa lama yang menganut pesugihan akan kaya raya. Kebanyakan pesugihan itu, salah satu syaratnya supaya cepat masuk ajian dan kekayaan, harus berdagang kuliner, dari sana kekayaan dan keuangan didapat. Sebagaimana cerita Mamat (nama samaran teman dan punyai isteri yang bekerja di salah satu rumah makan di Kalsel) dan pemiliknya kaya raya dalam waktu singkat. Menurut paparan Mamat, ada tumbal yaitu isteri atau keluarga dekat yang dipersembahkan oleh pemilik pesugihan ke bosnya, jin yang memberi kekayaan.

\section{Pesugihan jalan kanan}

Jenis pesugihan ini memang melakukan ritual-ritual wirid, puasa, belampah, berdasarkan bimbingan guru spiritual. Misalnya puasa di hari Jum'at, malam hari membaca bismillâh 1000x, membaca fâtihah 1000x, salawat 313x dan lahaulawalâquwwa Illa billâh 41 kali. Amalan ini diijazahkan oleh ulama terkenal di di Kalimatan Selatan. Karena yang menerima ijazah tidak mau disebut namanya dan termasuk nama gurunya, maka catatan di dalam pewawancaraan ada. Walaupun nama samaran juga tidak mau.

Amalan sembahyang tasbih dan salat Dhuha 16 Rakaat setiap hari tanpa putus selama hidup juga salah satu amalam. Rahasianya kalau dikerjakan di bulan puasa dan terutama di waktu ganjil sejak 21 Ramadhan, Insya Allah ditemui khadam Lailatul qadr. Pada bulan Ramadhan dan hari lilikuran itu, dilakukan, maka kekayaan akan melimpah ruah, walaupun yang diminta bukan uang atau harta benda, kalau seseorang ditemui Lailatul Qadr. Para ulama besar menurut Basari (bukan nama sebenarnya) termasuk yang dapat keistimewaan ini, begitu juga kaya $\mathrm{H}$ Ijai, Binuang, H Ciut selain orang tua kakek dan neneknya keturunan ulama, yang pernah diberi kekeramatan Lailatul Qadr, sampai tujuh turunan. Terbukti sekarang mereka masih kaya raya. Hal itu diamini oleh Pak Usuf (bukan nama senenarnya kapala satpam pom bensin H. Ijai). 
Amalan kedua, yaitu membaca salawat fulus dan salawat nariyah berjamaah sebanyak 4444 kali setiap malam Jumat dan siang hari bersedekah terhadap anak yatim sesuai kemampuan, insya Allah kaya raya sepanjang hidup dan tidak pernah mengalami kekurangan uang sedikit pun. Hal ini menurut Hj. Aisy, dilakukan beliau karena susah hidup, rumah menyewa, berjualan di kaki lima. Mendapatkan ijazah itu dengan seorang ulama besar dan diamalkan, akhirnya sampai sekarang, mereka hidup berkelimpahan uang.

Amalan lampahan jadi, yaitu berupa rajahan duit dari recehan, sampai 100 ribu diserahkan kepada guru spritual, dan hasil rajahan yang sudah ditirakati selama 41 hari disimpan di celengan uang untuk berdagang. Insya Allah akan mengalami kemajuan pesat dalam berdagang. Sebut saja namanya $\mathrm{Hj} \mathrm{NPH}$, yang pernah melakukan itu sebagai syarat berdagang dan sudah ditanyakan ke tuan guru tidak menyalahi syariat dan tidak syirik.

Bentuk tirakat pesugihan langka, yang masih dianggap jalan kanan adalah berupa tetesan air mata orang tua saat sakaratul maut dan saat dimandikan mayatnya. Air mata ayah, diambil dan disega dengan kain kapas bujang, kemudian disimpan di dalam dompet dengan disertai doa-doa khusus. Insya Allah dianggap sebagai wafaq penglaris dagang yang memiliki efek untung luar biasa. Anak yang bersangkutan tidak berapa lama akan kaya raya dan sukses. Hasil wawancara dengan UKS, nama samaran yang melakukan itu, dan mendapatkan ilmu tersebut dari seorang habib "tersembunyi" dan tidak mau disebutkan namanya. Menurut responden yang satu ini, rata-rata kalau mampu mengikuti atau menunggui orang tua laki-laki dengan selalu mendoakan di samping beliau saat meninggal dunia. Di dalam hati kita juga meminta agar orang tua berkenan mendoakan kita supaya sukses hidup, saat itu orang tua terharu dan meninggal dunia dalam keadaan menangis mendoakan anaknya. Sampai sudah dimandikan pun air matanya "sidin" mengalir deras seperti orang masih hidup. Air mata doa orang tua itu yang diambil dan dijadikan "ajimat” ampub meraib kekayaan dan keberlimpaban uang.

\section{Pesugihan jalan lurus}

Pesugihan ini merupakan pesugihan biasa-biasa saja namun memiliki kekayaan dan keuangan yang luar biasa juga, terutama salah satu intinya adalah mendapatkan warisan, atau kaya digaris nasib atau dijamak Jibril. Seperti didapatkan oleh AHD. Nama samaran, yang secara tibatiba mendapatkan warisan dari paman (saudara ayahnya) ratusan milyar baik berupa uang, emas, tanah rumah, gedung, toko-toko yang tersebar di sana-sini sebelum pamannya meninggal dunia. Padahal pamannya itu, sampai sekarang juga masih hidup, namun tidak mempunyai anak, jadi kebetulan ada ponakannya yang cocok, maka secara waris hibah setelah dipotong warisan ke saudara dan saudara isterinya. Warisan hibah itulah yang membuat AHD kaya raya.

Responden lain lain namanya BDI (samaran), yang mendapatkan warisan tanah kebun, tanah pahumaan sawah ratusan hektar. Setelah bapaknya meninggal dunia, maka jadilah ia orang kaya baru, setelah warisan saudara saudaranya dipotong, tetap saja ia dianggap kaya tanpa susah payah.

Analisis pustaka selama ini memang belum ada yang membahas topik makalah ini, kecuali yang dilakukan Sani dkk. dalam penelitian Sosiologis dan Kepercayaan Masyarakat Banjar PUSLIT IAIN Antasari Banjarmasin 2012. Di antara beberapa uraian prilaku kontemporer orang Banjar adalah terdapat istilah OKB (Orang Kaya Baru) yang memiliki relevansi tentang pengusaha 
batu bara baik sukses dan menjadi pengusaha benar-benar maupun mereka yang memiliki bidang usaha lain, namun juga sukses. Termasuk di antara beberapa pengungkapan tentang berbagai cerminan pesugihan seperti pesugihan Lailatul Q adr, hanya saja uraian lebih banyak membeber berbagai prilaku bisnis orang Banjar dalam kaitan berdagang Selebihnya berisi tentang berbagai kepercayaan masyarakat Banjar. ${ }^{5}$

Menarik juga ditelisik penelitian Ahmad Shagir dkk tentang Teologi Bisnis Ulama Banjar PUSLIT IAIN ANTASARI Tahun 2011 tentang berbagai ajaran dan prilaku kepercayaan ulama Banjar terkait dengan keterlibatan mereka di dunia perdagangan dan bisnis termasuk juga amaliah dan kepercayaan apa yang sesungguhnya mendorong ulama "wajib" kaya dan memiliki usaha legal halal dan mendapatkan keuntungan, intinya agar mereka dapat membiayai dakwah dan pendidikan dan tidak membebankan jamah maupun umat Islam yang lain.

Berbentuk buku atau kitab ada yang menarik, sebagai bahan analisis perbandingan misalnya kitab Imam Ghazali, Kitabul Aufaq, terbitan aneka Solo 1989, ${ }^{6}$ Miftah Ahnan, Kitab Ilmu Hikmah, penerbit Aneka Surabaya, 1986 dua bahan rujukan ini walaupun sumber pustaka belum sepenuhnya menjajal keyakinan dan secara praktik perlu pembuktian bahwa ajaran amaliah di dalam kitab atau buku dimaksud memiliki daya bukti real untuk mendapatkan kekayaan baik harta benda maupun uang Namun paling tidak bahwa ajaran Islam baik berdasarkan sumber utama (Alquran dan Sunnah) maupun warisan amaliah ulama dianggap mejadi bahan pertimbangan untuk mendukung pengenalan dasar "semi teori" atau paling tidak disebut doktrin kepercayaan.

Berbagai pelacakan diperlukan untuk kajian pustaka bandingan, misalnya Supriyanto memiliki advertorial promosi tentang Ilmu Gendam dan cara mendatangkan uang lewat kemampuan cipta pikiran, dalam leftlet dimaksud menjadi bahan isnpirasi, apakah imajinasi dan kekuatan pikiran terutama otak tengah dengan gelombang elektromagnetik telepati sanggup melakukan "keajaiban-keajaiban" dan dapat dibuktikan keilmiahannya? Jawaban pustaka diperlukan dengan menelusuri bahkan sedikit mendedar gambaran "kekuatan pikiran” otak tengah dan otak kanan Misalnya buku Ahmad Thoha Abdul Ghani tentang Praktik Pesugihan Islami dan Pesugihan Wali Songo 2009 Majlis Zikir Sapujagad Cakra Jaya Pamungkas Boyolali $2011 .^{7}$

Syaiful Maghsri, Bio Energy, Yogyakarta 2010, merupakan sebuah buku menciptakan peternakan uang menurut klasifikasi standar keilmuan buku ini mendedar dengan kerangka ujicoba berpuluh-puluh tahun dan sudah lazim dilakukan para ilmuan Jepang dan Eropa dalam rangka mendongkrak "Cahaya Batin dan Daya Cipta Pikiran untuk diarahkan kepada lompatan inovasi dan kreativitas otak hati dan spiritual agar dapat menghasilkan keajaiban hidup baik material maupun spiritual (metafisis) Masih banyak buku-buku bahan rujukan, namun kesemuanya itu dijadikan bahan pustaka kelengkapan nantinya untuk pengkajian makalah 2012).

${ }^{5}$ Sani, Abdul dkk., dalam penelitian Sosiologis dan Kepercayaan Masyarakat Banjar, (Banjarmasin:PUSLIT IAIN Antasari

${ }^{6} \mathrm{Al}-$ Ghazali, Kitab al-Aufaq, kata pengantar buku, (Jateng:Aneka Solo, 1986), h. ii-iv. Lihat juga pengarang yang sama, Syamsul Maarif, (tth.ttp), h. 17.

${ }^{7}$ Abdul Ghani, Ahmad Thoha, Pesugihan Islami, Pedepokan dan Majlis Zikir Sapujagad Jaya Pamungkas, (Boyolali: Bintang Songo, 2011). 
sekaligus bahan analisis. ${ }^{8}$ Termasuk juga berbagai primbon kekayaan dan melihat prospek hari baik dalam bekerja mencari nafkah.Lihat Abi Faliki, sebuahkitab berbahasa Melayu terbitan Medan Jaya, yang memuat salah satu, adalah cara menghitung dan membuka pintu rejeki berdasarkan angka lahir dan hari baik. ${ }^{9}$

Menurut analisis pustaka, bahwa ketiga jalan mendapatkan kekayaan secara prilaku sosial dapat diindentifikasikan kepada dua saja, yaitu jalan kanan (halal) dan jalan kiri (menyimpang/ tidak sesuai syara. Walaupun demikian kedua jalan ternyata secara ayaan dalam realitas, terjadi di masyarakat, walaupun masih dianggap mitos dan sulit dibuktikan terutama jalan kekayaan legendaris baik jalan kiri atau jalan kanan. Namun secara rasional semua jalan, termasuk sebagai jalan metarasional dan supra-rasional atau para rasional. Karena dapat dibuktikan dalam fakta pengalaman dan fakta sejarah riwayat kekayaan yang didapat yang dilakukan berdasarkan sebabmusabab ada yang sunatullah ada juga khawariqul addah.

Segi prilaku sebenarnya sama orang mendapatkan kekayaan dengan jalan berdoa, bekerja dan mendapatkan hasil. Hanya doa dan cara yang berbeda-beda ada yang Ilahi, manusiawi, namun ada juga yang syaitani. Jadi jalan-jalan perlu analisis kehati-hatian juga, termasuk ekspon cara mendapatkan kekayaan, misalnya dengan bantuan jin, minyak tertentu, dan amalan tertentu serta ajimat tertentu, semuanya merupakan cara. Cara itu dapat diamati, dan dikaji mendalam. Cara itu ada fakta dan data realitas prilaku, simbolisme yang dalam teori Blummer dan weber berarti dalam lingkup prilaku sosial seseorang karena berhubungan dengan aksi (tindakan) dan simbol tindakan. ${ }^{10}$ Tidak perlu apapun hasil dari tindakan, yang jelas faktualisasi ada prilaku di dalam perbuatan dan sikap yang dilakukan seseorang. Identitas prilaku jelas, dari hubungan sosial dalam interaksi terhadap seseorang menurut Ritzer, G. Teori Sosiologi Klasik dan Modern s. ada hal-hal tertentu, yang membuat seseorang mendorong melahirkan tindakan. Dari analisis bandingan dan analisis sederhana ini, ditemukan tiga tipe pesugihan yang dimunculkan dalam analisis klasifikasi makalah ini.

\section{DAFTAR PUSTAKA}

Abdul Ghani, Ahmad Thoha (2011). Pesugihan Islami, Pedepokan dan Majlis Zikir Sapujagad Jaya Pamungkas, Bintang Songo Boyolali.

Abi Paliki, (tth). Abi Ma'syar al-Falaki al Kabir, bahasaMelayu, Abi Ma'syar al-Falaki al-Kabir, Medan Jaya.

al-Ghazali, (1989). Kitabul Aufaq, Aneka Solo.

, (tth). Syamsu al-Maarif, ttp.

Brujomusti, (2013). edisi Liberty 443, Pakar Pasugihan Lampung.

Mantra, Edisi Tahun 2012, Majalah Bulanan.

Liberty, Edisi Tahun 2013, bundel tahunan, Surabaya.

Ritzer, G, (tth). Teori Sosiologi Klasik dan Modern, ttp.

${ }^{8}$ Syaiful Maghsri, Membedah Otak Kanan Bio Energi Senter, mendongkrak kekayaan lewat kapsul bioenergi, (Yogyakarta: 2013),h. 13-19.

${ }^{9}$ Abi Paliki, Abi Ma'syar al-Falaki al Kabir, bahasavMelayu, Abi Ma'syar al-Falaki al-Kabir, (Medan Jaya, tth).

${ }^{10}$ Lihat G. Ritzer. Teori Sosiologi Klasik dan Modern, (tth.: ttp). h. 356. 
Sani, Abdul dkk,(2012). dalam penelitian Sosiologis dan Kemercayaan Masyarakat Banjar Banjarmasin: PUSLIT IAIN Antasari.

Sangkanparan, Hartono, (2010). Membedah Otak Tengah; Dabsyatnya Otak Tengah,Jakarta: Visi Media.

Shagir, Ahmad, dkk, (2011). Teologi Bisnis Ulama Banjar,Banjarmasin: Puslit Iain Antasari.

Supriyanto, (Oktober 2011). Raja Gendam Jalanan, Tabloid POSMO.

Tambusai, Musdar Mustamam, (2010). Buku Pintar Jin Sibir Ruqvah Shariyah, Jakarta: Pustaka Al-Kausatsar.

Tanhoe, Khairul Anam, Moh. Ali, (Edisi Januari 2014).Hipnotis Beternak Uang, POSMO. 